\title{
Desempenho de frangos em diferentes densidades de pastejo: características das forrageiras, perdas por pastejo e consumo de alimento $^{1}$
}

\section{Poultry performance in different grazing densities: forage characteristics, losses due to grazing and feed intake}

\author{
Luciano Cristiano França²; Josiane Aparecida de Lima ${ }^{3 *}$ \\ Flávia Maria de Andrade Gimenes ${ }^{3}$; Vicente José Maria Savino ${ }^{4}$; \\ Antonio Augusto Domingos Coelho ${ }^{4}$; Claudia Cristina Paro de $\mathrm{Paz}^{3}$
}

\section{Resumo}

Avaliaram-se características morfológicas de três espécies forrageiras pastejadas por frangos caipira em lotação contínua. As forrageiras coastcross, capim-quicuio e estilosantes, foram implantadas em piquetes de $33 \mathrm{~m}^{2}$ com duas densidades ( $\mathrm{m}^{2} /$ frango): $\mathrm{D}_{1}=3 \mathrm{~m}^{2} /$ frango e $\mathrm{D}_{2}=1 \mathrm{~m}^{2} /$ frango. O delineamento foi em blocos completos casualizados, sendo um fatorial $3 \times 2$ (três forrageiras e duas densidades) e três repetições. Avaliaram-se altura do dossel forrageiro, massa de forragem, composição morfológica (folha, colmo e material morto), perdas por pastejo, ganho de peso dos frangos e consumo, conversão do concentrado e eficiência alimentar dos frangos. Ao final do período experimental as massas de forragem e de folhas foram consideradas baixas para o estilosantes na $D_{2}\left(0,28\right.$ e $\left.0,03 \mathrm{~kg} / \mathrm{m}^{2}\right)$ e para o capim-quicuio na $\mathrm{D}_{1}\left(0,13\right.$ e $\left.0,05 \mathrm{~kg} / \mathrm{m}^{2}\right)$ e $\mathrm{D}_{2}\left(0,11\right.$ e $\left.0,03 \mathrm{~kg} / \mathrm{m}^{2}\right)$ respectivamente, além da baixa altura do dossel forrageiro para esta gramínea $(6,50 \mathrm{~cm})$, podendo comprometer a entrada de novo lote de frangos. As três espécies forrageiras proporcionaram ganho de peso semelhante, sendo constatado melhor resultado para $3 \mathrm{~m}^{2} /$ frango (3,20 kg/frango). As forrageiras coastcross, capim-quicuio e estilosantes, com algumas ressalvas, podem ser consideradas adequadas para pastejo de frangos em engorda na densidade de $3 \mathrm{~m}^{2} /$ frango na época do ano avaliada (outono).

Palavras-chave: Avicultura alternativa, bem-estar animal, Cynodon spp. cv. Coastcross-1, Pennisetum clandestinum, Stylosanthes sp

\footnotetext{
Abstract

Morphological characteristics of three forage species grazed by rustic poultry in stocking were evaluated. Coast-cross fodder, kikuyu grass, and stylosanthes were planted in $33-\mathrm{m}^{2}$ paddocks with two densities

${ }^{1}$ Parte da dissertação do primeiro autor, estudante do curso de Mestrado em Produção Animal Sustentável, Instituto de Zootecnia, IZ, Nova Odessa, SP.

${ }^{2}$ Discente do Curso de Mestrado em Produção Animal Sustentável, Instituto de Zootecnia, IZ, Nova Odessa, SP. E-mail: lucrsfran@ gmail.com

${ }^{3}$ Prof $^{\text {s }}$ Dr $^{a_{s}}$ de Pós-Graduação em Produção Animal Sustentável, Pesquisadora Científica do IZ, Nova Odessa, SP. E-mail: josiane@ iz.sp.gov.br; flavia@iz.sp.gov.br

${ }^{4}$ Profs. Drs. do Dept ${ }^{\text {}}$ de Genética da Escola Superior de Agricultura "Luiz de Queiroz", ESALQ/USP, Piracicaba, SP. E-mail: vicente.savino@usp.br ; aadcoelh@usp.br

* Autor para correspondência
} 
( $\mathrm{m}^{2} /$ animal): $\mathrm{D}_{1}=3 \mathrm{~m}^{2} /$ animal and $\mathrm{D}_{2}=1 \mathrm{~m}^{2} /$ animal. The design was a randomized complete block with a $3 \times 2$ factorial (three grasses and two densities) and three replications. Grass canopy height, grass mass, morphological composition (leaf, stem, and dead material), losses due to grazing, poultry weight gain and consumption, and concentrate feed conversion ratio and efficiency were evaluated. At the end of the experiment, forage and leaves masses were considered low to stylosanthes in $\mathrm{D}_{2}\left(0.28\right.$ to $\left.0.03 \mathrm{~kg} / \mathrm{m}^{2}\right)$ and to kikuyu grass in $\mathrm{D}_{1}\left(0.13\right.$ to $\left.0.05 \mathrm{~kg} / \mathrm{m}^{2}\right)$ and in $\mathrm{D}_{2}\left(0.11\right.$ and $\left.0.03 \mathrm{~kg} / \mathrm{m}^{2}\right)$, respectively. In addition, the grass canopy height was considered low for stylosanthes $(6.50 \mathrm{~cm})$ that could jeopardize the entry of new poultry lot. The three grass species had similar weight gain and revealed better results for $3 \mathrm{~m}^{2} /$ chicken (3.20 kg/animal). Coast-cross fodder, kikuyu grass, and stylosanthes, with some exceptions, can be considered suitable for grazing fattening poultry at $3 \mathrm{~m}^{2} /$ animal at the evaluated time of the year (autumn).

Key words: Alternative poultry, animal welfare, Cynodon spp. cv. Coastcross-1, Pennisetum clandestinum, Stylosanthes sp

\section{Introdução}

A criação de frango caipira vem se destacando no Brasil e no mundo na última década (CARRIJO; MENEZES; SILVA, 2002), tornando-se uma atividade lucrativa. A criação de aves em sistema alternativo (pastejo), além da qualidade e do valor agregado ao produto final, busca a melhoria no bem-estar animal possibilitando que a ave expresse seu comportamento natural.

Diante da obrigatoriedade do sistema alternativo de criação em oferecer acesso a um pasto, a escolha da espécie forrageira, além de levar em consideração as exigências da espécie, deve ser baseada também nas necessidades das aves, como: baixo porte, boa aceitabilidade e digestibilidade (considerandose que as aves são animais monogástricos e com baixa digestibilidade de fibras), ricas em vitaminas e minerais. Além disso, devem apresentar bom enraizamento e potencial de rebrotação, garantindo, assim, a perenização e a produtividade do pasto.

Há inúmeras plantas forrageiras que podem ser utilizadas para o pastejo de aves. Conforme Silva e Nakano (1998), além do capim-quicuio e da gramaseda, os cultivares de Cynodon (Tifton e Coastcross) são boas opções de plantas forrageiras para aves. Por sua vez, o capim-quicuio é uma excelente alternativa na alimentação de aves devido ao seu alto potencial de produção, sendo também recomendado por Coelho, Savino e Rosário (2008). A utilização do estilosantes (Stylosanthes sp.) na alimentação de aves é citada em pesquisas realizadas na China e na Índia, proporcionando aumentos no ganho de peso e reduzindo a utilização de grãos e o custo na formulação das dietas (RAMESH, 2004).

Estudos relativos ao sistema alternativo de criação de aves contribuirão com o setor avícola, pois disponibilizarão opções de criação com menor gasto de insumos alimentares, além de agregar valor ao produto, tornando-o diferenciado e satisfazendo a uma classe de consumidores cada vez mais expressiva. Diante do exposto, objetivouse avaliar no período do outono, as características morfológicas de três espécies forrageiras pastejadas por frangos caipira suplementados com concentrado, bem como o desempenho e o consumo dos mesmos, e a conversão da ração concentrada e eficiência alimentar dos frangos.

\section{Material e Métodos}

O experimento foi realizado no Departamento de Genética da Escola Superior de Agricultura "Luiz de Queiroz"USP, localizada no município de Piracicaba Estado de São Paulo, entre os meses de abril e junho/2010. O solo da área foi classificado como Nitossolo Vermelho eutroférrico típico, com textura argilosa A moderada (SANTOS; JACOMINE; ANJOS, 2006). As características químicas do solo, para a camada de $0-20 \mathrm{~cm}$, evidenciaram alta fertilidade: $\mathrm{pH} \mathrm{CaCl}_{2} 5,7$; matéria orgânica $40,0 \mathrm{~g}$ / $\mathrm{dm}^{3}$; fósforo $(\mathrm{P}) 98,0 \mathrm{mg} / \mathrm{dm}^{3}$, potássio $(\mathrm{K}) 11,0$ 
$\mathrm{mmol}_{\mathrm{c}} / \mathrm{dm}^{3}$; cálcio (Ca) 77,0 $\mathrm{mmol}_{\mathrm{c}} / \mathrm{dm}^{3}$; magnésio (Mg) 23,0 $\mathrm{mmol}_{\mathrm{c}} / \mathrm{dm}^{3}$; capacidade de troca de cátions $139,0 \mathrm{mmol}_{\mathrm{c}} / \mathrm{dm}^{3}$; saturação por bases (V\%) $80 \%$. Os valores de $\mathrm{pH}$, níveis médios de fósforo e potássio e a saturação por bases foram considerados adequados aos requerimentos das forrageiras, não havendo a necessidade de fertilização e calagem. Os dados climáticos (Tabela 1) referentes ao período de preparo do solo para implantação das forrageiras até o fim da coleta de dados foram obtidos na estação experimental do Departamento de Engenharia e Biossistemas - ESALQ/USP.

Tabela 1. Temperaturas (mínima, máxima e média), precipitação pluviométrica e insolação média.

\begin{tabular}{cccccc}
\hline Mês/Ano & $\begin{array}{c}\text { Temp. Max. } \\
\text { Média }\left({ }^{\circ} \mathrm{C}\right)\end{array}$ & $\begin{array}{c}\text { Temp. Min. } \\
\text { Média }\left({ }^{\circ} \mathrm{C}\right)\end{array}$ & $\begin{array}{c}\text { Temp. Média } \\
\left({ }^{\circ} \mathrm{C}\right)\end{array}$ & $\begin{array}{c}\text { Precipitação } \\
\text { mensal }(\mathrm{mm})\end{array}$ & $\begin{array}{c}\text { Insolação média } \\
(\mathrm{h} / \text { dia })\end{array}$ \\
\hline ago/09 & 26,3 & 13,2 & 19,7 & 61,4 & 7,1 \\
set/09 & 27,6 & 16,8 & 22,2 & 143,8 & 5,2 \\
out/09 & 28,6 & 17,1 & 22,8 & 56,7 & 6,6 \\
nov/09 & 31,7 & 20,1 & 25,9 & 196,5 & 6,9 \\
dez/09 & 25,9 & 19,7 & 24,6 & 274,3 & 5,5 \\
jan/10 & 30,2 & 20,3 & 25,3 & 250,2 & 4,7 \\
fev/10 & 31,8 & 20,2 & 26,0 & 158,6 & 7,6 \\
mar/10 & 30,5 & 19,2 & 24,9 & 99,0 & 6,6 \\
abr/10 & 28,4 & 16,7 & 22,5 & 76,4 & 7,6 \\
mai/10 & 25,6 & 13,2 & 19,4 & 24,4 & 7,1 \\
jun/10 & 25,7 & 10,3 & 17,9 & 16,7 & 8,4 \\
\hline
\end{tabular}

Fonte: Departamento de Engenharia e Biossistemas, ESALQ/USP (2010).

Foram estudadas as espécies de forrageiras: coastcross (Cynodon spp. cv. Coastcross-1), capim-quicuio (Pennisetum clandestinum Hochst. ex Chiov) e estilosantes (Stylosanthes capitata e S. macrocephala - componentes do cultivar Estilosantes Campo Grande) submetidas ao pastejo contínuo por frangos, em três densidades: $\mathrm{D}_{1}\left(3 \mathrm{~m}^{2} /\right.$ frango $), \mathrm{D}_{2}\left(1 \mathrm{~m}^{2} /\right.$ frango $)$ e $\mathrm{D}_{3}\left(0,5 \mathrm{~m}^{2} /\right.$ frango $)$. $\mathrm{Na}$ $\mathrm{D}_{3}\left(0,5 \mathrm{~m}^{2} /\right.$ frango $)$ os pastos em todas as repetições foram completamente degradados aos 40 dias de pastejo, antes do final do período experimental, e não puderam mais ser utilizados. Esses tratamentos foram retirados do experimento, sendo a metodologia e resultados descritos considerando somente as duas densidades $\left(\mathrm{D}_{1}\right.$ e $\left.\mathrm{D}_{2}\right)$. Os demais tratamentos serão descritos como C1 e C2, E1 e E2, Q1 e Q2 (respectivamente, coastcross, estilosantes e capimquicuio nas densidades 1 e 2). O delineamento experimental foi em blocos completos casualizados, em esquema fatorial $(3 \times 2)$, sendo três espécies forrageiras, duas densidades e três repetições.

Aárea total com cada espécie forrageira foi de 198 $\mathrm{m}^{2}$, divididos em seis piquetes de $33,0 \mathrm{~m}^{2}$. O preparo do solo, realizado em agosto/2009, consistiu de uma aração e duas gradeações niveladoras. O plantio das forrageiras foi realizado após ocorrência de chuvas. O controle de plantas daninhas foi realizado com a utilização de enxada durante todo o período de estabelecimento do pasto até a primeira avaliação. Este procedimento foi realizado com o intuito de evitar que as plantas invasoras interferissem no desenvolvimento das plantas forrageiras.

O coastcross e o capim-quicuio foram plantados por meio de mudas com espaçamento de $0,50 \mathrm{~m}$ entre sulcos e o estilosantes semeado em linha com espaçamento de $0,40 \mathrm{~m}$ entre as mesmas. Realizou-se um corte de uniformização em todas as forrageiras um dia antes da entrada dos frangos nos 
piquetes (22/04/2010), padronizando-as em altura aproximada de $30 \mathrm{~cm}$.

Foram utilizados pintos de um dia provenientes da linhagem de frango 'caipira alternativa', sendo escolhida a linhagem 'Carijó Pesado' com aptidão para corte, sexados e definidos como machos com a finalidade de evitar variâncias de peso e consumo decorrentes de lotes mistos (machos e fêmeas). Durante todo o período experimental ração concentrada e água foram fornecidos à vontade. A composição das rações (concentrados) e os níveis calculados são apresentados na Tabela 2. A partir do primeiro dia de idade os pintinhos foram alojados em galpões recebendo concentrado idêntico e permanecendo em círculos de proteção com água e concentrado à vontade, aquecimento por meio de campânulas elétricas e iluminação no período noturno. Cada galpão comportava cerca de 400 animais que foram mantidos no mesmo ambiente até o $15^{\circ}$ dia, quando foram separados em seus respectivos boxes/piquetes e tratamentos e passaram do regime intensivo para semiconfinamento ou alternativo.

Tabela 2. Composição $(\mathrm{g} / \mathrm{kg})$ e valores calculados dos concentrados.

\begin{tabular}{ccc}
\hline Ingredientes & ${ }^{1}$ Inicial & ${ }^{2}$ Engorda \\
\hline Milho & 606,3 & 680,0 \\
Farelo de trigo & 25,0 & 20,0 \\
Farelo de soja & 312,5 & 237,5 \\
Óleo de soja & 4,1 & 10,4 \\
Suplemento & 52,1 & 52,1 \\
\hline Valores calculados & & \\
\hline EM $(\mathrm{kcal} / \mathrm{kg})$ & 3,000 & 3,150 \\
PB $(\mathrm{g} / \mathrm{kg})$ & 200,0 & 170,0 \\
Cálcio $(\mathrm{g} / \mathrm{kg})$ & 9,2 & 9,0 \\
Fósforo disponível $(\mathrm{g} / \mathrm{kg})$ & 3,0 & 2,9 \\
\hline
\end{tabular}

${ }^{1}$ Enriquecimento por $\mathrm{kg}$ de ração: ácido fólico $0,6 \mathrm{mg}$; antioxidante $100 \mathrm{mg}$; coccidiostático $100 \mathrm{mg}$; promotor de crescimento 40 mg; cobre $8 \mathrm{mg}$; ferro $50 \mathrm{mg}$; iodo 1,4 mg; lisina 0,35 g; manganês $72 \mathrm{mg}$; metionina 1,8 g; selênio 0,2 g; sódio 1,6 g; vit. A 8000 UI; vit. B12 15 mcg; vit. D3 3000 UI; vit. E 20 mg; vit k3 1,5mg; zinco 54,15 mg; pantotenato de cálcio 12 mg; niacina 40 mg; cloreto de colina 0,34 g; biotina $100 \mathrm{mcg}$; Piridoxina $3 \mathrm{mg}$; tiamina $2 \mathrm{mg}$; riboflavina $6 \mathrm{mg}$.

${ }^{2}$ Enriquecimento por $\mathrm{kg}$ do produto: ácido fólico $0,4 \mathrm{mg}$; antioxidante $100 \mathrm{mg}$; coccidiostático $60 \mathrm{mg}$; promotor de crescimento 30 mg; cobre $65 \mathrm{mg}$; ferro $50 \mathrm{mg}$; iodo $1 \mathrm{mg}$; lisina 0,3 g; manganês $60 \mathrm{mg}$; metionina 1,35 g; selênio 0,2 mg; sódio 1,5 g; vit. A 6000 UI; vit. B12 10 mcg; vit.D3 2000 UI; vit.E 10 mg; vit k3 0,80 mg; zinco 45 mg; pantotenato de cálcio 8 mg; niacina 20 mg; cloreto de colina $0,24 \mathrm{~g}$;

biotina $60 \mathrm{mcg}$; piridoxina $2 \mathrm{mg}$; tiamina $1,8 \mathrm{mg}$; riboflavina $4,5 \mathrm{mg}$.

Fonte: Elaboração dos autores.

As avaliações a seguir relacionadas ocorreram a cada 14 dias a partir do acesso dos frangos aos piquetes e transcorreram até o final do experimento, totalizando cinco períodos: aos 14, 28, 42, 56 e 70 dias de permanência dos frangos nos piquetes e, deste ponto do texto em diante, as mesmas serão referidas como Períodos 1, 2, 3, 4 e 5, respectivamente.

A altura do dossel forrageiro foi determinada por meio de medições semanais ( 15 pontos por piquete) utilizando-se uma régua de madeira, construída a partir de uma haste graduada em centímetros e, ao centro, foi colocada uma folha de transparência. Quando a haste atingia o solo realizava-se a leitura da altura na haste onde a transparência parava. A determinação da forragem disponível foi realizada por meio de corte (tesoura de poda), no nível do solo, em áreas delimitadas por quadrados de $0,09 \mathrm{~m}^{2}$ 
$(0,30 \mathrm{~m} \times 0,30 \mathrm{~m})$ colocados em três pontos no piquete (ao centro e nas extremidades). O material coletado foi separado nos componentes morfológicos folha (lâminas foliares), colmo (bainha foliar + colmo) e material morto.

A coleta das amostras para estimar a perda de forragem por pastejo foi realizada segundo a metodologia descrita por Carnevalli et al. (2006) em três locais fixos de $0,09 \mathrm{~m}^{2}(0,30 \mathrm{~m}$ x $0,30 \mathrm{~m})$ de cada piquete. Nestas áreas todo material solto sobre o solo e preso na planta, mas danificado pela ação dos animais foi colhido. Após dois dias, as áreas eram novamente visitadas e todo o material considerado perdido por pastejo novamente recolhido, seco em estufa e pesado para ser expresso em $g$ de matéria $\mathrm{seca} / \mathrm{m}^{2}$.

O ganho médio de peso dos frangos foi obtido pela diferença entre o peso vivo final e inicial. O peso inicial foi considerado quando os mesmos contavam com 15 dias (idade na qual foram separados por tratamento e acomodados em seus respectivos boxes/piquete) e o peso final foi realizado aos 85 dias de idade, quando encerraram as avaliações. O ganho de peso total/área foi obtido pela soma do ganho de peso dos frangos de cada piquete e dividido pela área $\left(\mathrm{m}^{2}\right)$. $\mathrm{O}$ consumo médio diário do concentrado foi estimado por meio da pesagem do concentrado fornecido e da sobra do mesmo, em cada período. O cálculo para determinar a conversão alimentar (CA) foi realizado pela relação entre a média de consumo diário de concentrado ( $\mathrm{g} /$ frango/ dia) e o ganho médio diário de peso ( $\mathrm{g} / \mathrm{frango} /$ dia). A eficiência alimentar (EA) foi calculada pela relação entre ganho médio de peso diário (g/frango/dia) e a média de consumo médio diário de concentrado $(\mathrm{g} /$ frango/dia).

A análise de variância dos dados foi realizada utilizando-se o PROC MIXED do pacote estatístico SAS (Statistical Analysis System). Os efeitos de planta forrageira, densidade de frangos, períodos e suas interações foram considerados fixos e o efeito de blocos foi considerado aleatório. As médias dos tratamentos foram estimadas usandose o LSMEANS e a comparação entre elas, quando necessária, realizada por meio da probabilidade da diferença (PDIFF), usando o teste de Tukey a 5\%. Para análise dos dados de ganho de peso total por área foi utilizado o procedimento GLM do mesmo pacote estatístico, adotando-se o nível de significância de 5\%.

\section{Resultados e Discussão}

A altura do dossel forrageiro variou conforme a interação planta forrageira $\mathrm{x}$ densidade $\mathrm{x}$ período $(\mathrm{P}=0,0426)$. Para o desempenho dos frangos ainda há necessidade de se estabelecer as melhores faixas de altura do dossel para utilização em cada espécie forrageira, mas para as forrageiras há indicativos das faixas mais adequadas, visando promover produtividade de forragem e perenidade do pasto, dois atributos desejados também para o sistema alternativo de criação de frangos.

Ao longo do período experimental o estilosantes manteve-se com as maiores alturas de dossel (Figura 1) indicando que as densidades de frangos não foram intensas o suficiente para rebaixar a leguminosa, provavelmente por possuir colmos lenhosos e de difícil consumo. O coastcross sofreu redução em altura (Figura 1), porém situando-se acima da altura mínima para este cultivar sob lotação contínua descrita por Carnevalli et al. (2001) em experimento com ovinos. Para esses autores, a faixa de utilização do coastcross deve estar entre 10 e $20 \mathrm{~cm}$ de altura do dossel forrageiro, intervalo no qual o acúmulo de forragem foi semelhante e apresentou renovação de perfilhos suficiente para manutenção e perenidade (SBRISSIA et al., 2001), indicando que nessa condição de manejo, tanto a produção de forragem como a estabilidade do pasto são atingidas.

O capim-quicuio sofreu drástica redução em altura do dossel ao longo do período experimental, chegando ao Período 5 com valores iguais e muito baixos nas duas densidades (Figura 1). Carvalho et al. (2010) trabalhando com capim-quicuio sob 
lotação contínua (meta de $20 \mathrm{~cm}$ de altura) obtiveram média de valores de altura do dossel forrageiro que variaram de 15,6 a 18,6 cm, considerados adequados para essa forrageira. Deve-se considerar que o valor de $6,50 \mathrm{~cm}$ registrado no Período 5 está muito abaixo da altura recomendada, o que poderia levar o pasto à degradação. Este fato possivelmente ocorreu em função de se ter trabalhado com lotação fixa e em época do ano (outono) pouco propícia ao desenvolvimento das plantas forrageiras. Dessa forma, a entrada de um novo lote de frangos nos piquetes não seria recomendável, pois devido à época do ano na finalização do experimento (final de outono), os pastos não teriam condições favoráveis de crescimento, sendo indicada a vedação dos piquetes com capim-quicuio até a próxima época de chuvas (primavera/verão) para recuperação em um novo ciclo de crescimento da gramínea.

Figura 1. Altura do dossel de plantas forrageiras pastejadas por frangos em lotação contínua.

* Análise realizada em dados transformados SQRT(x).

Letras minúsculas comparam médias de tratamentos dentro dos períodos.

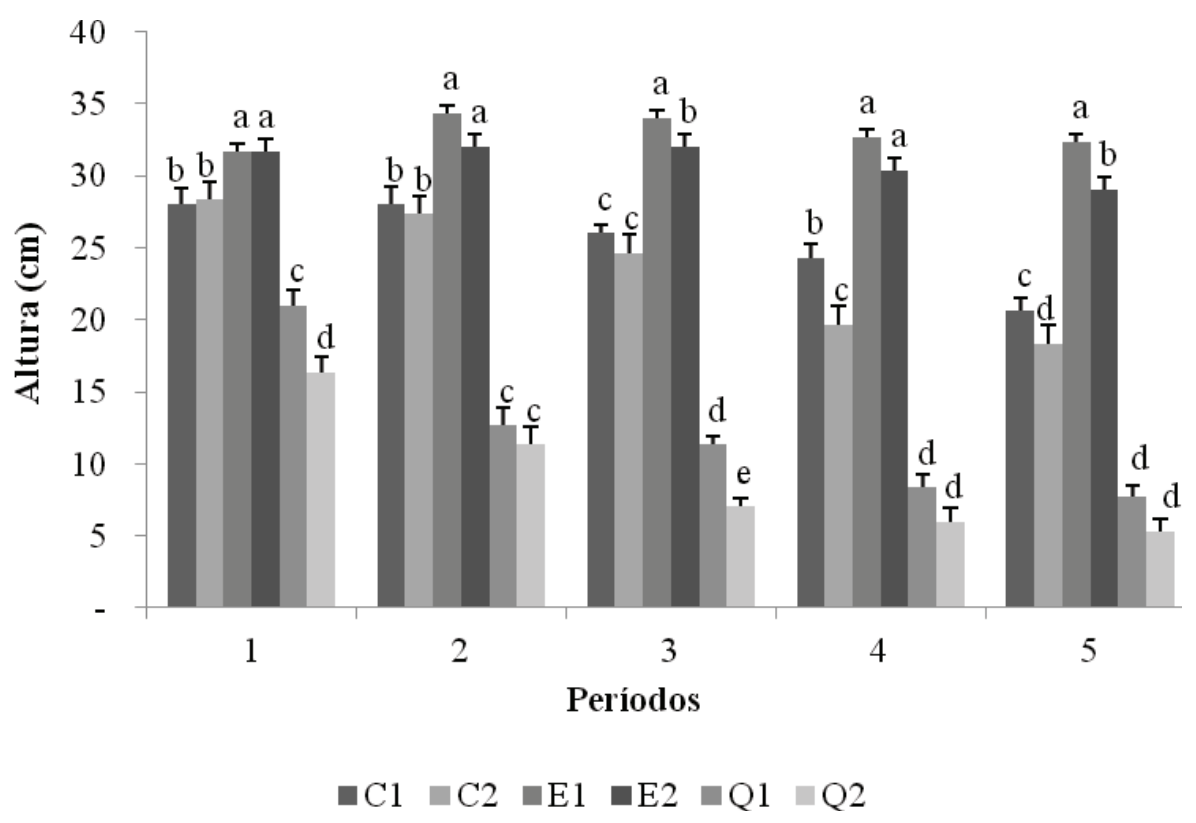

Fonte: Elaboração dos autores.

A massa total de forragem $\left(\mathrm{kg} / \mathrm{m}^{2}\right.$ de $\left.\mathrm{MS}\right)$ variou em função das interações planta forrageira $\mathrm{x}$ densidade $(\mathrm{P}=0,0409)$ (Tabela 3$)$ e densidade $\mathrm{x}$ período $(\mathrm{P}=0,0076)$ (Tabela 4$)$. De forma geral, houve redução da massa total de forragem (Tabela 4), bem como proporção de folhas e colmos (Figura 2 e Tabela 5) ao longo do período experimental, enquanto a proporção de material morto aumentou. Esse comportamento provavelmente ocorreu em razão do menor crescimento das plantas no outono (fatores de crescimento reduzidos) aliado ao consumo e injurias causados pelas aves. O capim-quicuio apresentou as menores massas de forragem, função do hábito de crescimento aliado a uma possível maior remoção de material vegetal realizada pelas aves nestes piquetes (Tabela 3 ), além da época do ano. Esses valores estão bem abaixo dos valores de massa de forragem registrados por Carvalho et al. (2010) para esta forrageira, com média de $0,26 \mathrm{~kg} / \mathrm{m}^{2}$, resultado compatível com a menor altura do dossel alcançada no presente experimento. A maior densidade de frangos $\left(D_{2}\right)$ 
causou redução na massa de forragem apenas para influenciadas pelas densidades (Tabela 3), apesar o estilosantes, evidenciando que em termos de da composição morfológica das mesmas ter sido massa total de forragem as gramíneas não foram alterada pelas densidades de frangos.

Tabela 3. Valores médios e erro padrão da média de massa total de forragem de plantas forrageiras pastejadas por frangos em lotação contínua, em função da espécie forrageira.

\begin{tabular}{lccc}
\hline \multirow{2}{*}{ Planta forrageiras } & \multicolumn{2}{c}{ Densidade $\left(\right.$ frangos $\left./ \mathrm{m}^{2}\right)$} & \multirow{2}{*}{ Média } \\
\cline { 2 - 3 } & \multicolumn{2}{c}{$\mathrm{D}_{1}\left(\mathrm{~kg} / \mathrm{m}^{2} \mathrm{de} \mathrm{MS}\right)$} & $0,17 \pm 0,01$ \\
\cline { 2 - 3 } coastcross & $0,16 \pm 0,01 \mathrm{Ba}$ & $0,17 \pm 0,01 \mathrm{Ba}$ & $0,34 \pm 0,01$ \\
estilosantes & $0,39 \pm 0,01 \mathrm{Aa}$ & $0,28 \pm 0,01 \mathrm{Ab}$ & $0,13 \pm 0,01$ \\
capim-quicuio & $0,13 \pm 0,01 \mathrm{Ca}$ & $0,11 \pm 0,01 \mathrm{Ca}$ & \\
\hline Média & $0,23 \pm 0,01$ & $0,19 \pm 0,01$ & \\
\hline
\end{tabular}

Médias seguidas por letras distintas, minúsculas nas linhas e maiúsculas nas colunas, diferem entre si $(\mathrm{P}<0,05)$.

$\mathrm{D}_{1}=3 \mathrm{~m}^{2} /$ frango, $\mathrm{D}_{2}=1 \mathrm{~m}^{2} /$ frango.

Fonte: Elaboração dos autores.

Tabela 4. Valores médios e erro padrão da média de massa de forragem total de plantas forrageiras pastejadas por frangos em lotação contínua, em função do período.

\begin{tabular}{cccc}
\hline \multirow{2}{*}{ Período } & \multicolumn{2}{c}{ Densidade $\left(\right.$ frangos $\left./ \mathrm{m}^{2}\right)$} & \multirow{2}{*}{ Média } \\
\cline { 2 - 3 } & \multicolumn{2}{c}{$\left(\mathrm{kg} / \mathrm{m}^{2} \mathrm{de} \mathrm{MS}\right)$} & \\
\cline { 2 - 3 } Período 1 & $0,27 \pm 0,01 \mathrm{Aa}$ & $0,26 \pm 0,01 \mathrm{Aa}$ & $0,27 \pm 0,01$ \\
Período 2 & $0,27 \pm 0,01 \mathrm{Aa}$ & $0,24 \pm 0,01 \mathrm{Ba}$ & $0,25 \pm 0,01$ \\
Período 3 & $0,21 \pm 0,01 \mathrm{Ba}$ & $0,17 \pm 0,01 \mathrm{Cb}$ & $0,19 \pm 0,01$ \\
Período 4 & $0,20 \pm 0,01 \mathrm{BCa}$ & $0,16 \pm 0,01 \mathrm{Ca}$ & $0,18 \pm 0,01$ \\
Período 5 & $0,19 \pm 0,01 \mathrm{Ca}$ & $0,11 \pm 0,01 \mathrm{Db}$ & $0,15 \pm 0,01$ \\
\hline Média & $0,23 \pm 0,01$ & $0,19 \pm 0,01$ & \\
\hline
\end{tabular}

Médias seguidas por letras distintas, minúsculas nas linhas e maiúsculas nas colunas, diferem entre si $(\mathrm{P}<0,05)$.

$\mathrm{D}_{1}=3 \mathrm{~m}^{2} /$ frango, $\mathrm{D}_{2}=1 \mathrm{~m}^{2} /$ frango.

Fonte: Elaboração dos autores.

Tabela 5. Valores médios e erro padrão da média para proporção de colmos de plantas forrageiras pastejadas por frangos em lotação contínua.

\begin{tabular}{|c|c|c|c|c|}
\hline \multirow{2}{*}{ Períodos } & \multicolumn{3}{|c|}{ Forrageiras } & \multirow{2}{*}{ Média } \\
\hline & coastcross & estilosantes & capim-quicuio & \\
\hline & \multicolumn{3}{|c|}{$(\mathrm{g} / \mathrm{kg}$ de $\mathrm{MS})$} & \\
\hline Período 1 & $405,2 \pm 24,5 \mathrm{Ab}$ & $576,6 \pm 1,0 \mathrm{Aa}$ & $333,0 \pm 2,45 \mathrm{Ac}$ & $438,3 \pm 14,1$ \\
\hline Período 2 & $402,7 \pm 13,4 \mathrm{Ab}$ & $496,6 \pm 13,4 \mathrm{Ba}$ & $356,3 \pm 1,34 \mathrm{Ac}$ & $418,5 \pm 07,7$ \\
\hline Período 3 & $388,0 \pm 26,6 \mathrm{ABab}$ & $444,5 \pm 26,6 \mathrm{Ca}$ & $346,7 \pm 2,66 \mathrm{Ab}$ & $393,0 \pm 15,4$ \\
\hline Período 4 & $391,6 \pm 14,2 \mathrm{ABb}$ & $453,9 \pm 14,2 \mathrm{Abc}$ & $275,5 \pm 1,42 \mathrm{Bc}$ & $373,7 \pm 08,2$ \\
\hline Período 5 & $349,9 \pm 24,1 \mathrm{Bb}$ & $463,9 \pm 24,1 \mathrm{BCa}$ & $275,5 \pm 2,41 \mathrm{Bc}$ & $359,4 \pm 13,9$ \\
\hline Média & $387,5 \pm 14,4$ & $487,1 \pm 14,4$ & $315,2 \pm 14,4$ & \\
\hline
\end{tabular}

Médias seguidas por letras distintas, minúsculas nas linhas e maiúsculas nas colunas, diferem entre si $(\mathrm{P}<0,05)$.

Fonte: Elaboração dos autores. 
A proporção de folhas na massa total de forragem ( $\mathrm{g} / \mathrm{kg}$ de MS) foi influenciada pela interação planta forrageira $\mathrm{x}$ densidade $\mathrm{x}$ período $(\mathrm{P}=0,0254)$. A proporção de folhas na massa total de forragem foi decrescente ao longo dos períodos avaliados (Figura 2). Para o coastcross (Figura 2) esteve acima da proporção descrita para o mesmo cultivar mantido a $20 \mathrm{~cm}$ de altura sob lotação contínua por ovinos, que variou de 168,0 a $167, \mathrm{~g} / \mathrm{kg}$ de MS para primavera e verão, respectivamente (CARNEVALLI et al., 2001). Essa diferença ocorreu, possivelmente, porque no experimento com ovinos o pasto foi mantido sob lotação contínua por longo período, o que contribuiu para elevar a proporção de material morto na base do dossel forrageiro, resultando em menor proporção de folhas; o que não ocorreu no presente estudo, em razão de um período experimental mais curto.

Figura 2. Proporção de folhas de plantas forrageiras pastejadas por frangos em lotação contínua. Letras minúsculas comparam médias de tratamentos dentro dos períodos.

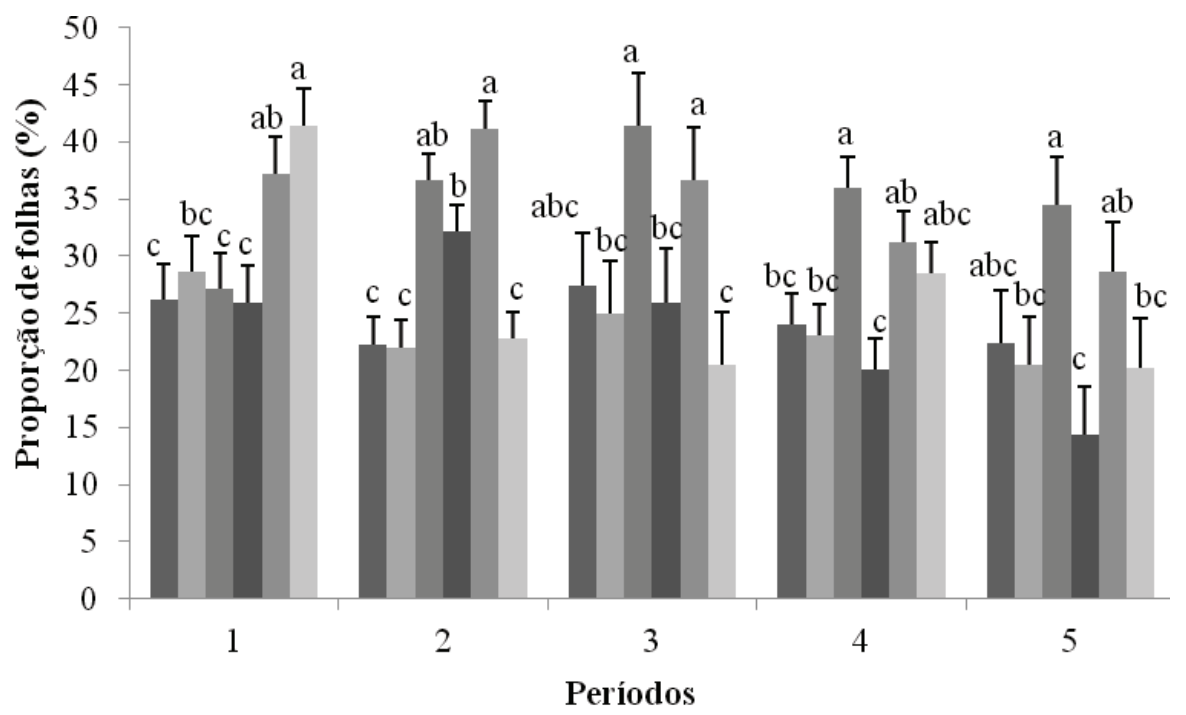

$\square \mathrm{C} 1 \square \mathrm{C} 2 \square \mathrm{E} 1 \square \mathrm{E} 2 \square \mathrm{Q} 1 \square \mathrm{Q} 2$

Fonte: Elaboração dos autores.

A massa de folhas $\left(\mathrm{kg} / \mathrm{m}^{2}\right)$ foi influenciada pela interação planta forrageira $\mathrm{x}$ densidade $\mathrm{x}$ período $(\mathrm{P}=0,0127)$ (Figura 3), de maneira geral com redução ao longo do período experimental. Esse fato é importante para o entendimento da manutenção da comunidade de plantas forrageiras ao longo dos ciclos de pastejo, pois com a redução neste componente as plantas terão redução no índice de área foliar (IAF) que está altamente correlacionado com a interceptação luminosa pelas plantas (HODGSON, 1990), com consequente redução na taxa de fotossíntese, o que irá comprometer as futuras produções de forragem. Considerando o exposto, a $\mathrm{D}_{2}$ foi a densidade que mais comprometeu as forrageiras, pois no Período 5 até mesmo o estilosantes, que apresentou os melhores resultados, teve a massa de folhas muito baixa na maior densidade (Figura 3), indicando que para esta leguminosa a densidade de frangos teve forte influência na massa foliar. Sendo assim, a densidade de $1 \mathrm{~m}^{2} /$ frango $\left(\mathrm{D}_{2}\right)$ não é a melhor densidade para esta época do ano (outono) devido à acentuada redução na massa de folhas e colmos das plantas forrageiras. 
A proporção de colmos ( $\mathrm{g} / \mathrm{kg}$ de $\mathrm{MS})$ na massa total de forragem variou em função interação planta forrageira $\mathrm{x}$ período $(\mathrm{P}=0,0008)$ sendo que as maiores proporções ocorreram no estilosantes e, as menores, no capim-quicuio com reduções ao longo do período experimental (Tabela 5). A massa de colmos $\left(\mathrm{kg} / \mathrm{m}^{2}\right.$ de $\left.\mathrm{MS}\right)$ apresentou diferenças significativas em relação a interação planta forrageira $\mathrm{x}$ densidade $\mathrm{x}$ período $(\mathrm{P}=0,0298)$, havendo redução em todos os tratamentos. Essas diferenças entre as plantas forrageiras no que se refere ao componente colmo podem ser atribuídas às diferenças morfológicas e de crescimento das espécies. Para ruminantes, elevada massa de colmos não é desejada por dificultar o consumo de forragem e comprometer a nutrição dos animais (HODGSON, 1990). Para aves, também não é desejada, mas por prejudicar o bem-estar das mesmas, já que os colmos são mais duros e podem dificultar a movimentação das aves nos piquetes, machucá-las e ser um obstáculo ao descanso e ao ato de ciscar. E, ainda, é importante considerar que os colmos têm menor valor nutritivo em relação às folhas.

Figura 3. Massa de folhas de plantas forrageiras pastejadas por frangos em lotação contínua.

Análise realizada em dados transformados SQRT(x)

Letras minúsculas comparam médias de tratamentos dentro dos períodos.

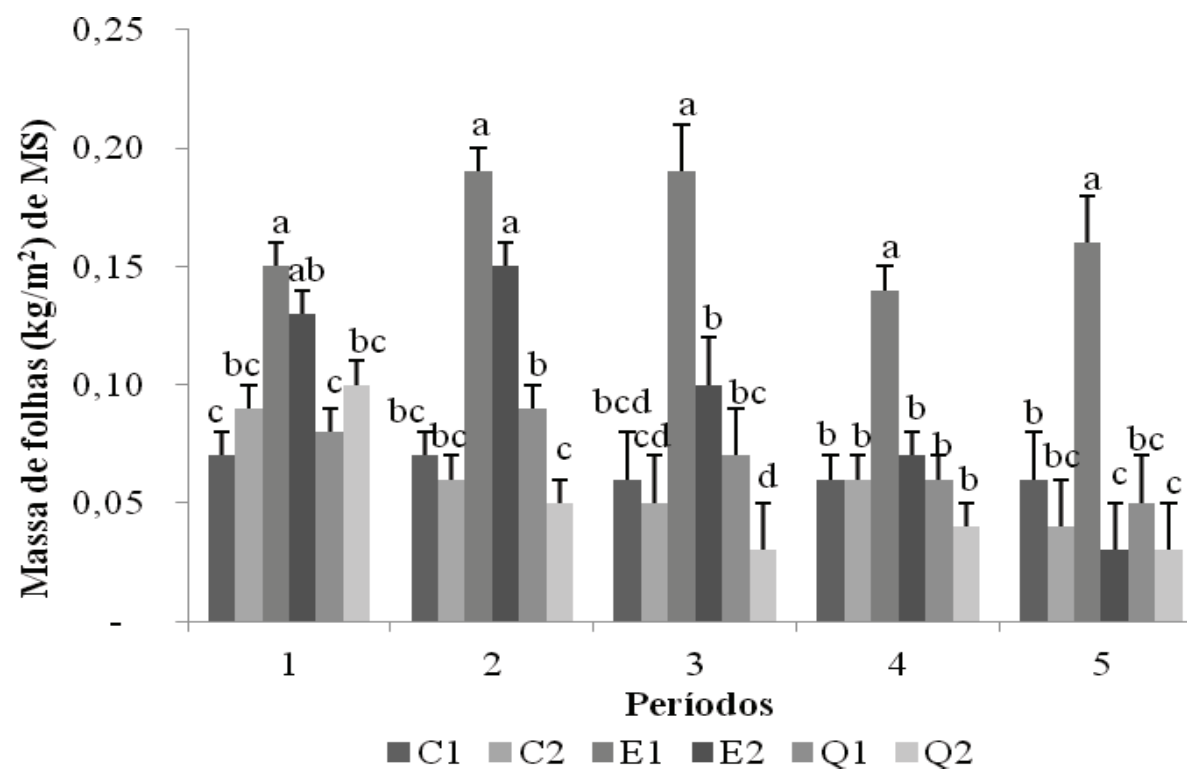

Fonte: Elaboração dos autores.

A proporção de material morto na massa total de forragem apresentou diferenças significativas conforme a interação planta forrageira $\mathrm{x}$ densidade $\mathrm{x}$ período $(\mathrm{P}=0,0005)$. No início do período experimental (Período 1), os valores foram superiores para coastcross $\left(0,09 \mathrm{~kg} / \mathrm{m}^{2}\right.$ de MS) e inferiores para capim-quicuio $\left(0,06 \mathrm{~kg} / \mathrm{m}^{2}\right.$ de MS $)$ e estilosantes $\left(0,08 \mathrm{~kg} / \mathrm{m}^{2}\right.$ de MS) que não diferiu dos demais. Ao longo do período experimental em todas as espécies forrageiras houve um incremento na proporção dessa variável, possivelmente resultado dos danos causados às plantas pelo ato de ciscar e ação de pastejo das aves. Além disso, deve-se considerar que a época do ano não favoreceu o crescimento das plantas e também o aumento na idade dos pastos pode ter influenciado no acúmulo de material morto. 
Houve efeito da interação planta forrageira $\mathrm{x}$ densidade $\mathrm{x}$ período $(\mathrm{P}=0,0417)$ em relação às perdas por pastejo. Para o coastcross, o aumento na densidade de frangos elevou a quantidade de forragem perdida, provavelmente gerada pelas injurias às plantas em função do ato de ciscar das aves; enquanto para o estilosantes, o aumento da densidade reduziu a quantidade de perdas, sugerindo que a forragem produzida foi melhor aproveitada pelos frangos e o porte mais arbustivo da leguminosa pode ter dificultado as injúrias (Figura 4). Nos Períodos 1 e 5 (inicio e final do experimento) não houve diferença entre os tratamentos (Figura 4), o que pode ter ocorrido em razão do comportamento das aves que ciscam em busca de alimento. Nesse contexto, é importante mencionar que a metodologia empregada para mensuração das perdas por pastejo foi a mesma empregada em experimentos de pastejo com ruminantes (CARNEVALLI et al., 2006), podendo, portanto, apresentar restrições, pois as aves ao ciscar podem misturar a forragem caída em outro local com a forragem proveniente da área dos quadrados de avaliação, ou retirar da área de avaliação o material que deveria fazer parte desta. Apesar dessa ressalva, os resultados foram interessantes na medida em que auxiliam na compreensão do que se passa entre a forragem produzida e a forragem consumida.

Figura 4. Perdas de forragem de plantas forrageiras pastejadas por frangos em lotação contínua. Letras minúsculas comparam médias de tratamentos dentro dos períodos.

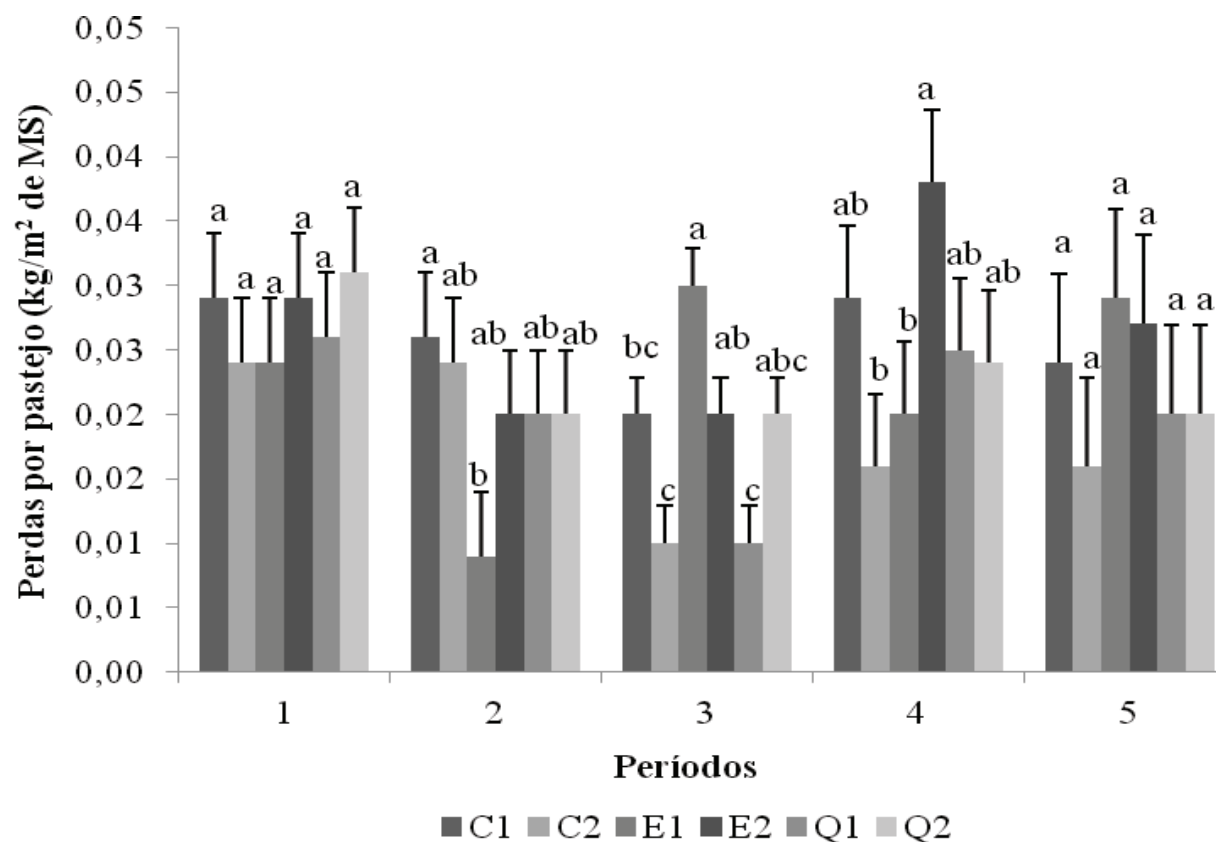

Fonte: Elaboração dos autores.

Para aves, a melhor cobertura do solo proporcionada pela deposição de material vegetal pode favorecer o bem-estar animal, pois este material contribui para a manutenção da umidade do solo, tornando-o menos compactado, o que beneficia a presença de minhocas, larvas e insetos e, ao mesmo tempo, reduz o contato das aves com o solo nos momentos de repouso.

O consumo total médio de concentrado não variou conforme a planta forrageira $(\mathrm{P}=0,0552)$ ou densidade de frangos $(\mathrm{P}=0,0958)$ e foi de 10,2 $\mathrm{kg}$ /frango (Tabela 6). Este consumo é próximo 
ao observado por Takahashi et al. (2006) que trabalharam com a linhagem Paraíso Pedrês por um período de 84 dias e obtiveram consumo de $9,2 \mathrm{~kg}$. Carrijo, Menezes e Silva (2002) em 55 dias de experimento constataram consumo de $7,9 \mathrm{~kg}$ de concentrado quando trabalharam com a mesma linhagem utilizada por Takahashi et al. (2006). A conversão e a eficiência alimentar também não foram influenciadas pelos tratamentos, cujos valores médios foram 3,3 e 0,31\%, respectivamente. Esse fato indica que o consumo das plantas forrageiras não causou efeito de substituição de concentrado.

Tabela 6. Valores médios e erro padrão da média (EP) para ganho de peso por frango e por área, consumo, conversão e eficiência alimentar do concentrado por frangos em pastejo em três espécies forrageiras submetidas à lotação contínua.

\begin{tabular}{|c|c|c|c|c|c|}
\hline \multirow{2}{*}{ Forrageiras } & \multicolumn{2}{|c|}{ Ganho de peso } & \multirow{2}{*}{$\begin{array}{c}\text { Consumo de } \\
\text { concentrado (kg/frango) }\end{array}$} & \multirow{2}{*}{$\begin{array}{l}\text { Conversão } \\
\text { alimentar }\end{array}$} & \multirow{2}{*}{$\begin{array}{l}\text { Eficiência } \\
\text { alimentar }\end{array}$} \\
\hline & (kg/frango) & $\left(\mathrm{kg} / \mathrm{m}^{2}\right)$ & & & \\
\hline coastcross & $3,12 \pm 0,06$ & $2,06 \pm 0,03$ & $9,9 \pm 0,49$ & $3,2 \pm 0,15$ & $0,33 \pm 0,02$ \\
\hline estilosantes & $3,14 \pm 0,06$ & $2,03 \pm 0,03$ & $9,9 \pm 0,49$ & $3,2 \pm 0,15$ & $0,32 \pm 0,02$ \\
\hline capim-quicuio & $3,07 \pm 0,06$ & $2,03 \pm 0,03$ & $10,6 \pm 0,49$ & $3,4 \pm 0,15$ & $0,29 \pm 0,02$ \\
\hline Média & 3,11 & 2,04 & 10,15 & 3,3 & 0,31 \\
\hline \multicolumn{6}{|l|}{ Densidade (m²/ave) } \\
\hline $\mathrm{D}_{1}$ & $3,20 \pm 0,054 \mathrm{a}$ & $1,06 \pm 0,03 \mathrm{~b}$ & $10,17 \pm 0,40$ & $3,2 \pm 0,12$ & $0,32 \pm 0,01$ \\
\hline $\mathrm{D}_{2}$ & $3,02 \pm 0,054 \mathrm{~b}$ & $3,01 \pm 0,03 \mathrm{a}$ & $10,13 \pm 0,40$ & $3,4 \pm 0,12$ & $0,30 \pm 0,01$ \\
\hline Média & 3,11 & 2,0 & 10,15 & 3,3 & 0,31 \\
\hline
\end{tabular}

Médias seguidas por letras distintas na coluna diferem entre si $(\mathrm{P}<0,05)$.

$\mathrm{D}_{1}=3 \mathrm{~m}^{2} /$ frango, $\mathrm{D}_{2}=1 \mathrm{~m}^{2} /$ frango.

Fonte: Elaboração dos autores.

O ganho médio de peso foi influenciado somente pela densidade $(\mathrm{P}=0,0326)$, sendo observado maior valor $(3,20 \mathrm{~kg})$ para a $\mathrm{D}_{1}$ em relação à $\mathrm{D}_{2}(3.02 \mathrm{~kg})$ (Tabela 6). Para ganho de peso total das aves por unidade de área $\left(\mathrm{kg} / \mathrm{m}^{2}\right)$, também houve diferença significativa $(\mathrm{P}<0,001)$ entre as densidades, sendo o maior ganho relativo à $\mathrm{D}_{2}$ (Tabela 6 ). $\mathrm{O}$ maior ganho médio de peso/frango registrado na menor densidade $\left(\mathrm{D}_{1}\right)$, possivelmente, está relacionado a menor competição por alimento devido ao maior espaço no piquete para cada ave $\left(3 \mathrm{~m}^{2} /\right.$ frango); além do maior espaço que confere bem-estar às aves, a $\mathrm{D}_{1}$ pode ter proporcionado maior consumo de outras fontes de alimento tais como insetos, larvas, minhocas, etc. Outro aspecto que deve ser levado em consideração é que na menor densidade de frangos $\left(D_{1}\right)$ houve maior massa de forragem em razão da menor competição entre as aves pelas plantas forrageiras, o que resulta, conforme já mencionado, em maior sombreamento e umidade do solo e esta condição torna o microclima favorável à proliferação de minhocas, insetos e larvas, que contribuem com a nutrição das aves. É importante ressaltar que não só a produtividade animal deve ser considerada, mas, também, a condição das forrageiras durante o período de pastejo e ao final de um ciclo de produção de frangos, visto que, em seguida virá um novo lote de animais e o pasto deve estar produtivo e sem sinais de degradação para recebê-los.

\section{Conclusões}

As plantas forrageiras coastcross, capim-quicuio e estilosantes são adequadas para pastejo de frangos na densidade de $3 \mathrm{~m}^{2} /$ ave. A densidade de $0,5 \mathrm{~m}^{2} /$ ave não é recomendada e a $\mathrm{D}_{2}\left(1 \mathrm{~m}^{2} /\right.$ frango $)$ deve ser usada com cautela, pois considerando a entrada 
de um novo lote de frangos após o período de avaliação (70 dias), o estilosantes e capim-quicuio apresentaram baixas massa de forragem, folhas e altura do dossel. Os pastos de coastcross sofreram menos os efeitos das densidades, chegando ao final do período de avaliação com altura e massa de forragem adequadas a um novo ciclo de pastejo em ambas as densidades $\left(1 \mathrm{~m}^{2} /\right.$ ave e $3 \mathrm{~m}^{2} /$ ave $)$.

\section{Referências}

CARNEVALLI, R. A.; DA SILVA. S. C.; FAGUNDES, J. L.; SBRISSIA, A. F.; CARVALHO, C. A. B.; PINTO, L. F. M.; PEDREIRA, C. G. S. Desempenho de ovinos e respostas de pastagem de Coastcross submetidas a regime de desfolha sob lotação contínua. Scientia Agricola, Piracicaba, v. 51, n. 1, p. 7-15, 2001.

CARNEVALLI, R. A.; SILVA, S. C.; OLIVEIRA, A. A.; UEBELE, M. C.; BUENO, F. O.; HODGSON, J.; SILVA, G. N.; MORAES, J. P. Herbage production and grazing losses in Panicum maximum cv. Mombaça under four grazing management. Tropical Grasslands, Queensland, v. 40, n. 3, p. 165-176, 2006.

CARRIJO, A. S.; MENEZES, G. P.; SILVA, M. J. Avaliação de linhagens alternativas na criação de frango tipo caipira. Revista Brasileira de Ciência Avícola, Campinas, v. 4, p. 84, 2002. Suplemento 1.

CARVALHO, P. F. C.; DEWULF, A. K. M. Y.; MORAES, A.; BREMM, C.; TRINDADE, J. K.; LANG, C. R. Potencial do capim-quicuio em manter a produção e a qualidade do leite de vacas recebendo níveis decrescentes de suplementação. Revista Brasileira de Zootecnia, Viçosa, MG, v. 39, n. 9, p. 1866-1874, 2010.
COELHO, A. A. D.; SAVINO, V. J. M.; ROSARIO, M. F. Frango feliz caminhos para avicultura alternativa. FEALQ: Piracicaba, 2008. 88 p.

ESALQ/USP. Série de dados climatológicos do Campus Luiz de Queiroz de Piracicaba, SP. Departamento de Engenharia de Biossistemas Escola Superior de Agricultura "Luiz de Queiroz" Universidade de São Paulo LEB - ESALQ - USP. São Paulo: USP, 2010.

HODGSON, J. Grazing management: science into pratice. New York: Longman Scientific and Technical, Longman Group, 1990. 203 p.

RAMESH, C. R. Anthracnose resistant stylosanthes for agricultural system. ACIAR- Australian Center for International Agricultural Research. Section B, chapter 11, 2004. p. 140-141.

SANTOS, H. G.; JACOMINE, P. K. T.; ANJOS, L. H. C. Sistema brasileiro de classificação dos solos. 2. ed. Rio de Janeiro: Embrapa Solos, 2006. 306 p.

SBRISSIA, A. F.; DA SILVA, S. C.; CARVALHO, C. A.; CARNEVALLI, R. A.; PINTO, L. F. M.; FAGUNDES, J. L.; PEDREIRA, C. G. S. Tiller Size/Population density compensation in grazed coastcross bermudagrass swards. Scientia Agricola, Piracicaba, v. 58, n. 4, p. 655-665, 2001.

SILVA, R. D. M.; NAKANO, M. Sistema caipira de criação de galinhas. Piracicaba: [s.n], 1998, 110 p.

TAKAHASHI, S. E.; MENDES, A. A.; SALDANHA, E. S. B. P.; PIZZOLANTE, C. C.; PELÍCIA, K.; GARCIA, R. G.; PAZ, R. G.; QUINTERO, R. R. Efeito do sistema de criação sobre o desempenho e rendimento de carcaça de frangos de corte tipo colonial. Arquivo Brasileiro de Medicina Veterinária e Zootecnia, Belo Horizonte, v. 58, n. 4, p. 624-632, 2006. 